\title{
Correction to: Characterization of feed coal and combustion by-products from Kemerkoy power plant in Turkey
}

\author{
Gul Akar Sen ${ }^{1} \cdot$ Hatice Yilmaz ${ }^{1} \cdot$ Sezai Sen ${ }^{1} \cdot$ Vedat Arslan $^{1} \cdot$ Uner Ipekoglu ${ }^{1}$
}

Published online: 29 May 2019

(C) Saudi Society for Geosciences 2019

Correction to: Arabian Journal of Geosciences (2019) 12:269 https://doi.org/10.1007/s12517-019-4433-x

The original version of this paper was published with error.

- The text on the diffractograms referring the peaks of the minerals is missing in Figure 3.

- The text on the particles referring the EDS points are missing in Figure 4.

- In Figure 5, the boiler schematic referring the locations which the samples were taken is missing and only 3 sample pictures were presented, there must be 6 sample pictures.

- The text on the particles referring the EDS points are missing in Figure 6.

Given in this article are the correct figures.

The online version of the original article can be found at https://doi.org/ 10.1007/s12517-019-4433-x

Sezai Sen

sezai.sen@deu.edu.tr

1 Department of Mining Engineering, Dokuz Eylul University, Buca, Izmir, Turkey 


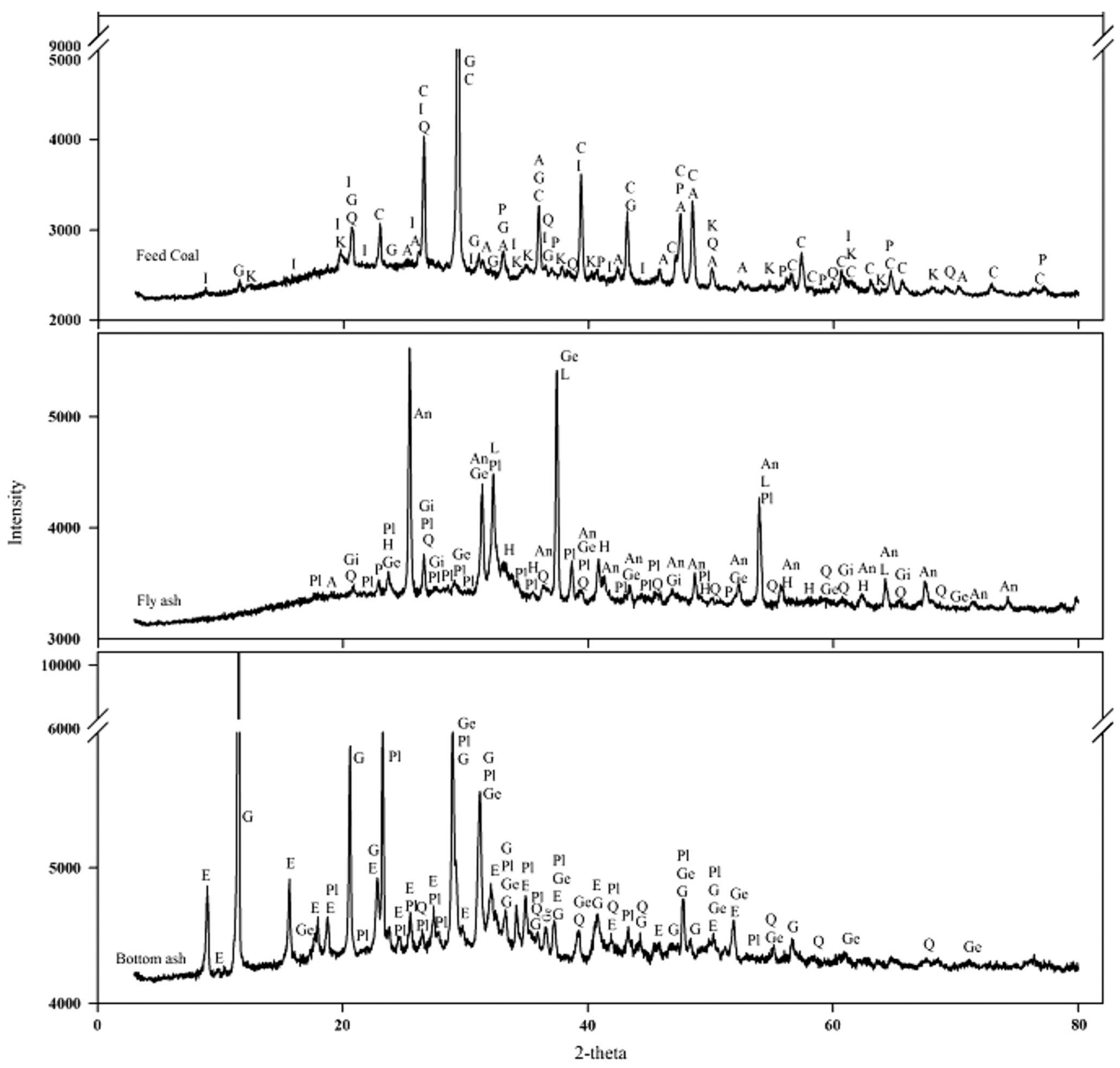

( $\mathrm{C}=$ Calcite, $\mathrm{Q}=$ Quartz, $\mathrm{P}=$ Pyrite, $\mathrm{I}=\mathrm{Ill}$ ite, $\mathrm{G}=$ Gypsum, $\mathrm{A}=$ Aragonite, $\mathrm{K}=$ Kaolinite, An=Anhydrite, $\mathrm{L}=\mathrm{L}$ ime, $\mathrm{H}=$ Hematite $\mathrm{Gi}=\mathrm{Gismondine}, \mathrm{E}=\mathrm{E}$ ttringite $, \mathrm{Ge}=\mathrm{Gehlenite}, \mathrm{Pl}=\mathrm{Plagioclase}$ )

Fig. 3 Results of mineralogy of coal samples and by-products 
Fig. 4 SEM images of the studied samples (a feed coal, b FA, c BA)
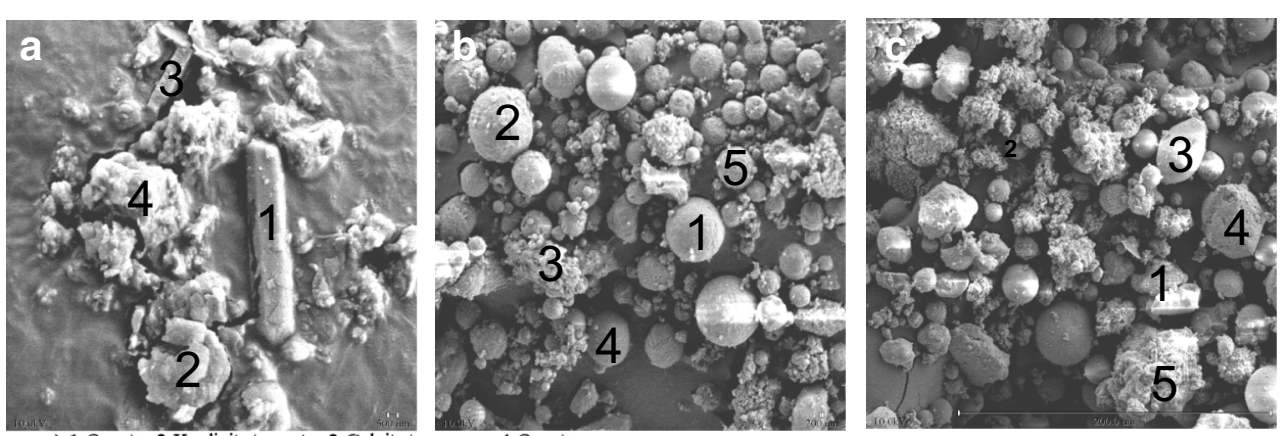

a) 1 Quartz, 2 Kaolinite $q u a r t z, 3$ Cacite+oypsum, 4 Quartz

b) 1-2 Lime+anyhdrite $+\mathrm{Ca}, \mathrm{Mg}, \mathrm{Al}$ silicates, 3 Lime+anyhdrite, 4-5 Hematite+anyhdrite

c) 1 Gypsum 2 Hematite+gypsum 3 Gehlenite 4-5 Gypsum+ ettringite+Ca, Al silicates
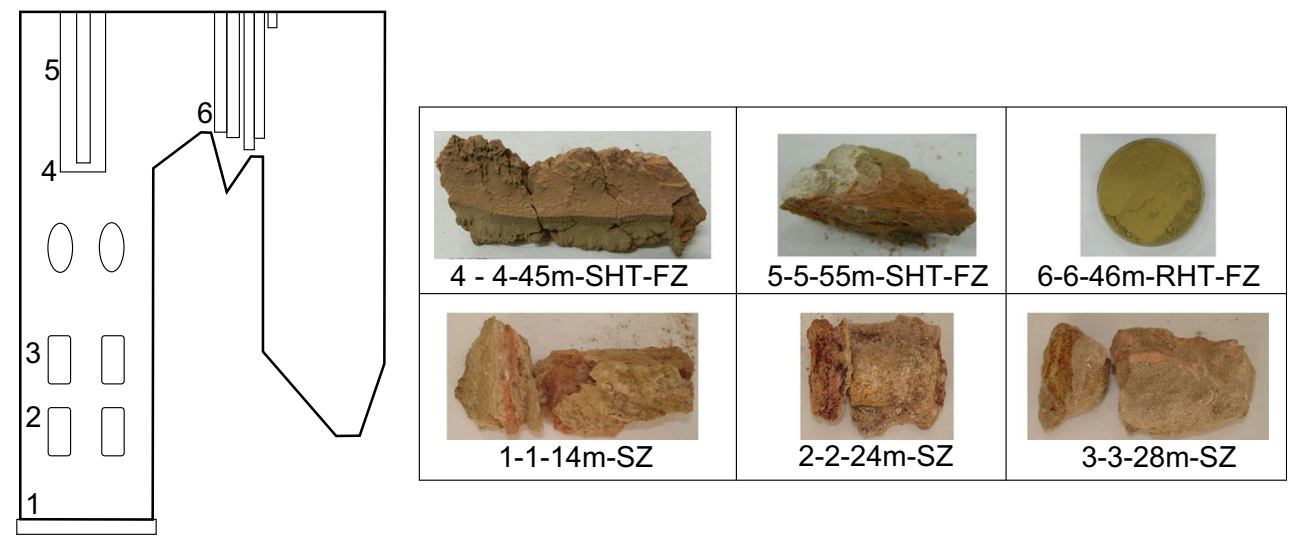

Fig. 5 Location and the macro-morphology of samples

Fig. 6 Secondary electron images of the SZ and FZ samples (SEMEDS results were given in Table 7)
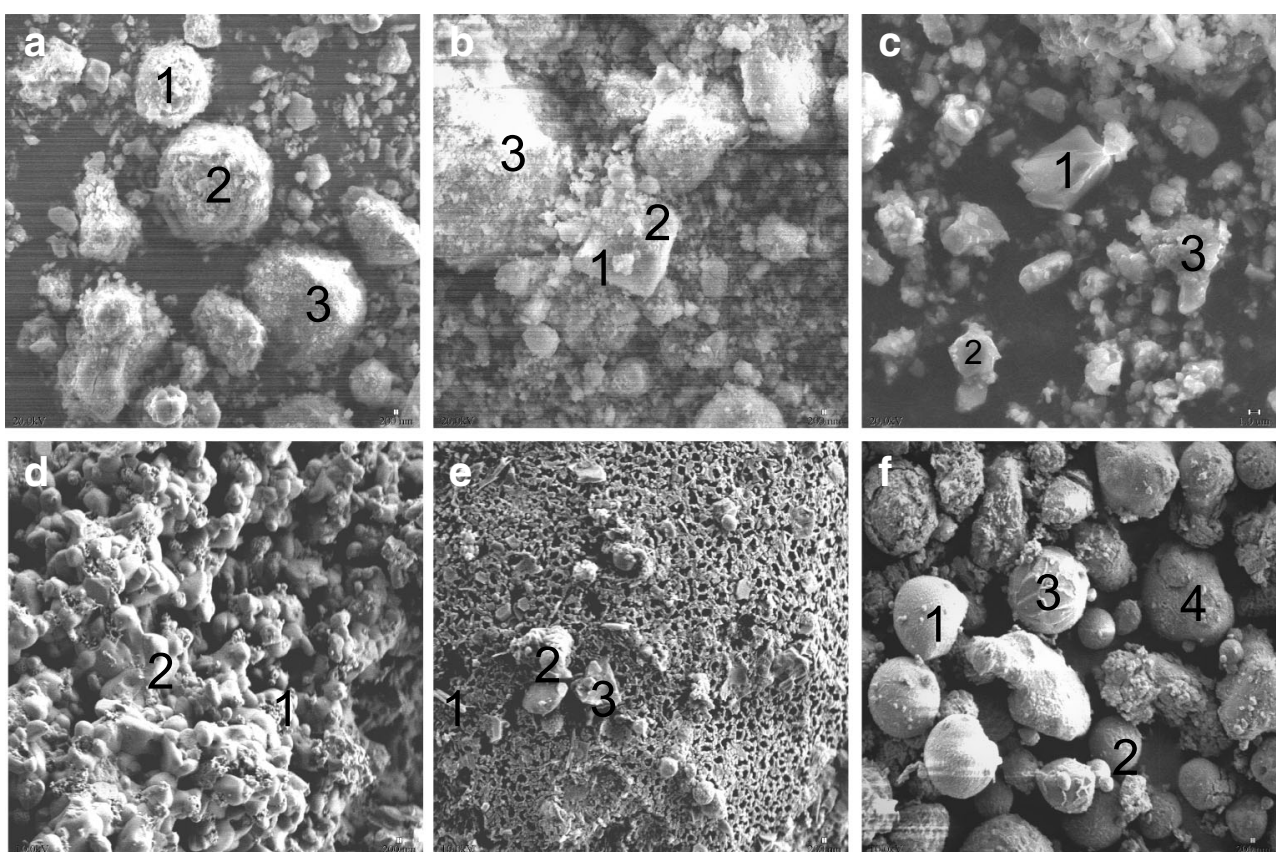

(a-14 $\mathrm{m}$ at mag nification of $720 \mathrm{x}, \mathrm{b}-24 \mathrm{~m}$ at magnification of $2000 \mathrm{x}, \mathrm{c}-28$ at mag nification of $1000 \mathrm{x} \mathrm{m}, \mathrm{d}-45 \mathrm{~m}$ SHT at magnification of $1000 \mathrm{x}, \mathrm{e}-55 \mathrm{~m} \mathrm{SHT}$ at magnification of $1000 \mathrm{x}, \mathrm{f}-46 \mathrm{~m}$ RHT at magnification of $1000 \mathrm{x}$ ) 